\title{
A pronúncia variável de /t, d/ diante de [i] na fala de migrantes sergipanos em São Paulo
}

DOI: http://dx.doi.org/10.21165/el.v50i3.2969

\section{Amanda de Lima Santana'}

\section{Resumo}

Este artigo analisa os usos de /t, d/ diante de [i], na fala de migrantes sergipanos residentes em São Paulo, pressupondo-se que eles estão mudando seu modo de falar de acordo com os contatos que estabelecem (ou não) com paulista(no)s. A partir de uma amostra com 27 entrevistas sociolinguísticas, de integrantes de duas redes sociais diferentes, testa-se a hipótese de que os sujeitos da rede aberta (que estabelecem mais contato com paulistas) palatalizam mais frequentemente /t, d/ em relação aos da rede fechada. Averigua-se também o efeito de outros fatores sociais e linguísticos. As análises revelam que idade de migração e sua interação com escolaridade são relevantes para os usos dos sujeitos: os que migraram mais jovens e que estudaram em São Paulo apresentam maiores taxas de palatalização. Dentre as variáveis linguísticas pertinentes ao fenômeno, estão sonoridade e contexto fonológico precedente.

Palavras-chave: contato dialetal; redes sociais; migrantes sergipanos; palatalização de $/ t, d /$.

1 Universidade de São Paulo (USP), São Paulo, São Paulo, Brasil; alsantana11@gmail.com; https://orcid.org/0000-0002-8047-100X 


\title{
The variable pronunciation of $/ t, d /$ before [i] in the speech of Sergipanos migrants living in São Paulo
}

\begin{abstract}
This article analyzes the usage of / $t, d /$ before [i] in the speech of Northeastern Brazilians from Sergipe residing in São Paulo, assuming that they are changing their speech according to the contacts established (or not) with Paulista(no)s. Using a sample constituted by 27 sociolinguistic interviews with members of two different social networks, this study tests the hypothesis that the ones who are part of the open network (with more contact with Paulistanos) palatalize more frequently / $t, d /$ than the ones who are part of the closed network. The effect of other social and linguistic factors was also verified. The analysis shows that the age of arrival and its interaction with the formal education level are relevant to the migrant's pattern of speech: the ones who migrated younger and studied in São Paulo show higher rates of palatalization. Among the linguistic variables relevant to the phenomenon are voicing and preceding phonological context.
\end{abstract}

Keywords: dialect contact; social networks; Sergipanos migrants; palatalization of /t, d/.

\section{Introdução}

A pronúncia das consoantes /t, d/ antes de [i], no português brasileiro, é um processo fonológico variável que diferencia dialetos. Enquanto os falantes de grande parte do Nordeste do país pronunciam, mais frequentemente, essas consoantes como oclusivas ([t, d]), na região Sudeste, há a predominância da pronúncia palatalizada ([t $\mathrm{f}$, dz]]). Além disso, de acordo com Abaurre e Pagotto (2013), existe uma tendência de avanço das formas palatalizadas no Brasil. Em razão de tal cenário de mudança, são muitos os trabalhos sobre essa variável, como Pagotto (2001), Battisti e Dornelles Filho (2015), Souza (2016), dentre outros.

Mais especificamente sobre as cidades de São Paulo e de Aracaju - as duas regiões em foco no presente estudo -, Cardoso et al. (2014), no Atlas Linguístico do Brasil, revelam uma expressiva diferença: a cidade de São Paulo apresenta uma pronúncia categórica das formas palatalizadas, enquanto, em Aracaju, a taxa de palatalização é somente de $16 \%$. Sendo assim, pode-se afirmar que tal traço fonético diferencia o falar paulista do sergipano. Então, em uma situação de contato dialetal, em que um sergipano migra para São Paulo, e considerando que a atitude positiva de um migrante em relação à comunidade anfitriã leva a mudanças em sua fala (TRUDGILL, 1986), pode-se esperar um aumento na taxa de palatalização desse sujeito.

A fim de investigar tal hipótese, analisaram-se 27 entrevistas sociolinguísticas realizadas com migrantes sergipanos de duas diferentes redes sociais (MILROY, 1987 [1980]) com 
o objetivo de verificar se os integrantes da rede aberta (caracterizada pelo contato mais frequente com paulista(no)s e por uma mobilidade geográfica maior) estão palatalizando mais do que os pertencentes à rede mais fechada (assim denominada pelo pouco contato com paulista(no)s e pela reduzida mobilidade geográfica). Ademais, buscou-se identificar, além do tipo de rede, outros fatores linguísticos e sociais que estão associados ao padrão de variação dos usos de /t, d/ na fala dessas pessoas.

Por meio da plataforma R ( $\mathrm{R}$ CORE TEAM, 2020), criaram-se modelos de regressão logística de efeitos mistos, em que o falante e o item lexical foram incluídos como variáveis aleatórias, para testar os dados extraídos das entrevistas. As variáveis linguísticas analisadas foram Sonoridade, Tonicidade, Contexto fonológico precedente, Contexto fonológico posterior e Status da vogal alta; enquanto as sociais foram Rede social, Idade de migração, Escolaridade e Sexo/gênero.

A análise dos dados revela, dentre outros resultados, que a principal hipótese da pesquisa não converge com os dados: não há diferenças significativas entre as taxas de palatalização dos migrantes da rede aberta e da fechada. Com efeito, os fatores sociais relevantes são idade de migração (aqueles que migraram mais jovens mais frequentemente produzem as formas palatalizadas), escolaridade (os menos escolarizados desfavorecem a palatalização) e a interação entre essas duas variáveis (os que migraram mais jovens e completaram seus estudos em São Paulo têm maiores estimativas de palatalização).

Ao longo deste artigo, tanto a metodologia quanto os resultados são explanados mais detalhadamente. Para isso, o texto se divide em quatro seções. Na primeira, apresentamse os dados sobre os usos de / $t$, $d /$ em diferentes regiões do Brasil, com referência aos trabalhos de Cardoso e colegas (2014) e de Abaurre e Pagotto (2013); também é descrito o estudo de Martins (2008), que versa sobre a variável em situação de contato dialetal; assim como se discutem brevemente algumas questões sobre a fala do migrante (TRUDGILL, 1986; SIEGEL, 2010). Ainda nessa seção, é apresentado o trabalho de BortoniRicardo (2011 [1985]) como um exemplo metodológico de como realizar o estudo da fala do migrante. Tal questão metodológica é desenvolvida na seção seguinte, em que são descritos o modo de coleta das entrevistas, os passos de codificação e extração dos dados e os testes estatísticos realizados. Posteriormente, expõem-se os resultados, juntamente com as análises interpretativas. 0 artigo termina com as considerações finais, onde aponta para a falta de dados de avaliação entre os falantes menos escolarizados e sugere como encaminhamento futuro da pesquisa a realização de entrevistas com migrantes com ensino superior para verificar se suas taxas de palatalização são ainda maiores do que aqueles que estudaram até o ensino médio. 


\section{Pressupostos teóricos}

As diferentes variedades do português brasileiro se distinguem, entre outros aspectos linguísticos, pela pronúncia de /t, d/ diante de [i]: enquanto alguns falares se caracterizam pela pronúncia oclusiva dos segmentos ([t, d]), outros apresentam a pronúncia palatalizada ([t $\left.\left.\int, d_{3}\right]\right)$. Na perspectiva fonológica, de acordo com Bisol e Hora (1993), a palatalização é concebida como a transformação de uma consoante simples em complexa devido à influência do traço [coronal] da vogal na conversão do traço [+anterior] para [-anterior] da consoante (ou seja, nesse processo, as oclusivas dentais diante de /i/ fonológico ou fonético derivado de /e/, em sílaba átona, resultam nas formas [t $\int$, dz] - como em dia e sete). De acordo com Abaurre e Pagotto (2013), existe uma tendência crescente à palatalização no Brasil e o estudo de tendência realizado por Battisti e Dornelles Filho (2015) mostra um exemplo desse crescimento ao comparar dados de duas amostras coletadas em Flores da Cunha (RS), uma de 1990, do banco de dados do Variação Linguística na Região Sul do Brasil (VARSUL), e outra de 2009, do Banco de Dados de Fala da Serra Gaúcha (BDSer).

No Atlas Linguístico do Brasil, Cardoso et al. (2014) fazem um panorama desse fenômeno linguístico nas diferentes regiões do país, como se vê na figura 1:

Figura 1. Distribuição das realizações palatais de /t, d/ diante de [i] nas capitais do Brasil

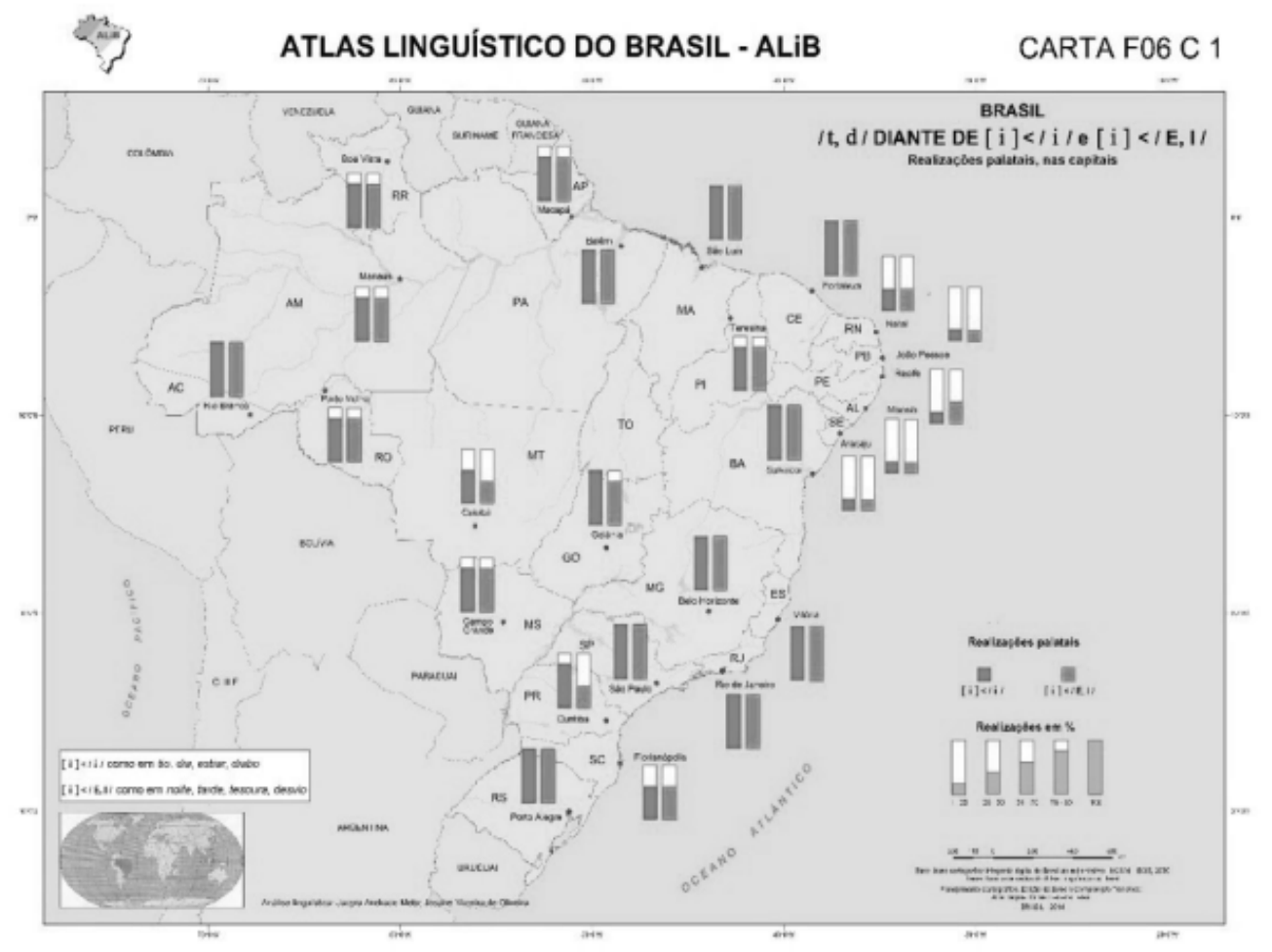

Fonte: Cardoso et al. (2014, p. 123, adaptado) 
Ao observar a figura 1, nota-se que nas cidades nordestinas Natal, João Pessoa, Recife, Maceió e Aracaju estão as menores frequências dos casos de palatalização². Compreendendo que as diferentes frequências de uso de determinadas variáveis diferenciam as variedades de uma mesma língua, fica claro, diante de tal cenário, que a pronúncia de /t, d/ é uma das características que distinguem o falar de Aracaju do de São Paulo. Ademais, além do nível fonético, essas variáveis podem ser de quaisquer outros níveis: morfossintático, lexical, prosódico ou pragmático (SIEGEL, 2010). Se há, portanto, tais diferenças, um indivíduo que migra de uma região dialetal para outra pode mudar o modo como fala ao longo dos anos (TRUDGILL, 1986), aproximando-se mais da fala da comunidade anfitriã (um sergipano que migra para São Paulo pode aumentar a taxa de palatalização de /t, d/, por exemplo). Assim, uma pesquisa sociolinguística que se volta para o estudo de um grupo de migrantes intenciona investigar quais são os fatores linguísticos e sociais que se relacionam ao processo de mudança que ocorre em sua fala. Afinal, em estudos com pressupostos labovianos, a língua é concebida como um sistema inerentemente heterogêneo e regulado, em que tanto fatores linguísticos quanto sociais se correlacionam a padrões observados na fala de um grupo de indivíduos (LABOV, 2008 [1972]).

A pesquisa realizada por Martins (2008) é um exemplo de estudo que se debruça sobre a fala do migrante com a preocupação de observar os fatores linguísticos e sociais envolvidos na mudança de um dialeto para outro. Com a análise de sete entrevistas sociolinguísticas realizadas com paraibanos residentes na cidade do Rio de Janeiro, a autora verificou se os informantes apresentavam altas taxas de palatalização de /t, d/ diante de [i], em direção ao dialeto carioca, que se caracteriza pela regra categórica da palatalização. Dos 1430 dados, Martins revela que 64\% foram palatalizados, evidenciando um distanciamento em relação ao falar de origem. A pesquisadora esclarece que o segmento surdo e as posições silábicas tônica e postônica são as variáveis linguísticas que mais favorecem a realização do fenômeno. Além disso, dentre os fatores sociais relevantes para o padrão de variação estão o tempo de permanência na comunidade anfitriã e o relacionamento positivo que o migrante tem em relação a ela.

Ao contrário de Martins (2008), que não utilizou dados de paraibanos não migrantes para calcular as diferenças estatísticas entre os dois grupos de falantes (migrantes versus não migrantes), a presente pesquisa opta por utilizar dados de Sergipe (o estado de origem dos migrantes aqui analisados) para estabelecer interpretações com embasamento estatístico. Nesse sentido, decidiu-se pela utilização dos resultados da pesquisa de Souza (2016), que analisou as frequências de usos de /t, d/ diante de [i] na fala de sergipanos universitários ou com ensino superior completo, de três cidades sergipanas (Aracaju, Lagarto e Itabaiana). O autor revela que são os sujeitos de Aracaju que mais palatalizam as consoantes (21,7\%), em comparação aos de Itabaiana $(7,7 \%)$ e Lagarto $(6,6 \%)$, mas a

2 As barras pretas, na figura, referem-se aos dados com vogal alta fonética (como em "saudade") e as barras mais claras representam os dados com vogal alta fonológica (como "direito"). 
pronúncia oclusiva dos segmentos ainda é muito recorrente nessas regiões, apesar de as formas palatalizadas serem mais prestigiadas pelos sergipanos. Com tais dados, é possível comparar as frequências entre o grupo que migrou e o que não migrou.

Para a análise da fala do migrante, como em qualquer outra pesquisa de Sociolinguística, é necessário que haja uma decisão sobre como se dará a coleta da amostra a ser estudada. Se a pesquisa parte do pressuposto de que os migrantes estão mudando seu jeito de falar por conta dos contatos rotineiros que estabelecem com aqueles que estão à sua volta, faz sentido construir uma amostra a partir do conceito de redes sociais (MILROY, 1987 [1980]; BORTONI-RICARDO, 2011 [1985]). Tais redes sociais podem ser descritas como teias infinitas de laços que se prolongam por toda a sociedade, agrupando os indivíduos entre si. Esses laços, por sua vez, podem ser fortes ou fracos: os primeiros são aqueles que agregam familiares e amigos, e os segundos interligam apenas conhecidos (MILROY; LLAMAS, 2013 [2002]). As diferenciações entre os laços interessam aos sociolinguistas na medida em que elas podem explicar os padrões de variação dos fenômenos linguísticos. Nesse sentido, a hipótese aventada é a de que é mais provável observar mais semelhanças nos modos de falar de pessoas interligadas por laços fortes do que por laços fracos.

Bortoni-Ricardo (2011 [1985]), por exemplo, desenvolveu um trabalho pioneiro na região administrativa de Brazlândia, em Brasília, sobre a fala de migrantes mineiros de regiões rurais com a análise das redes sociais estabelecidas pelos indivíduos. Através da criação de dois índices - o de integração nas redes e o de urbanização -, a autora partiu da hipótese de que quanto mais adiantado o migrante estivesse no processo de transição rural/urbano (isto é, com um alto índice de urbanização), mais ele produziria variantes características do "novo" dialeto. Em contrapartida, era esperado que as pessoas que tivessem estabelecido majoritariamente contatos com membros da família (também migrantes) e vizinhos, sem alcançar indivíduos inseridos na cultura dominante (urbana), estariam utilizando as variantes do dialeto de origem. A partir da análise de quatro variáveis linguísticas que diferenciavam os dialetos em foco ${ }^{3}$, Bortoni-Ricardo constatou que as mulheres tendiam a preservar a pronúncia de origem, uma vez que elas pouco saíam de casa, enquanto os homens interagiam mais com os nativos da comunidade anfitriã e, desse modo, entravam em contato, mais frequentemente, com a nova variedade linguística e a produziam mais.

O presente trabalho, inspirado em Bortoni-Ricardo (2011 [1985]), também se vale de uma amostra construída a partir do conceito de redes sociais para o estudo da pronúncia variável de /t, d/ diante de [i] na fala de sergipanos residentes em São Paulo. A próxima seção esclarece como se deu a construção de tal amostra.

3 Vocalização do fonema alveopalatal lateral em posição intervocálica; redução dos ditongos crescentes em finais de palavras; concordância verbal variável na $1^{\text {a }}$ e na $3^{a}$ pessoa do plural. 


\section{A constituição do corpus e as estratégias de análise}

Santana (2018) ${ }^{4}$, motivada pelos trabalhos de Milroy (1987 [1980]) e de Bortoni-Ricardo (2011 [1985]), construiu uma amostra de fala com a coleta de entrevistas sociolinguísticas realizadas com migrantes sergipanos de duas redes sociais. A construção da amostra começou com dois informantes, uma mulher e um homem, que não se conheciam. Ambos foram os pontos de partida para a construção das redes. A entrevista englobou perguntas sobre a infância, o período escolar, o trabalho, as diferenças entre São Paulo e Sergipe, entre outros aspectos. Finalizada a gravação, perguntava-se aos informantes quais eram as dez pessoas com quem eles mais mantinham contato no dia a dia (e as respostas abrangiam membros da família, vizinhos ou colegas de trabalho), e tanto os nomes dessas pessoas quanto seu estado de origem eram anotados pela pesquisadora. A coleta continuava com a realização de novas entrevistas (que duravam entre 40 e 90 minutos) com aqueles indivíduos citados que também eram sergipanos, e assim sucessivamente. A maioria das pessoas indicadas aceitou gravar as entrevistas ${ }^{5}$, contudo, algumas delas não quiseram participar.

O corpus, então, é formado por 27 entrevistas sociolinguísticas realizadas com migrantes sergipanos que moram em São Paulo, Osasco, Carapicuíba, Cotia e Taboão da Serra (cidades da região metropolitana de São Paulo). A rede fechada integra 16 pessoas (9 mulheres e 7 homens) e a aberta é constituída por 11 pessoas (4 mulheres e 7 homens), como se observa na figura 2.

Figura 2. Representações gráficas das redes dos migrantes entrevistados ${ }^{6}$ (a rede fechada aparece à esquerda e a rede aberta, à direita)

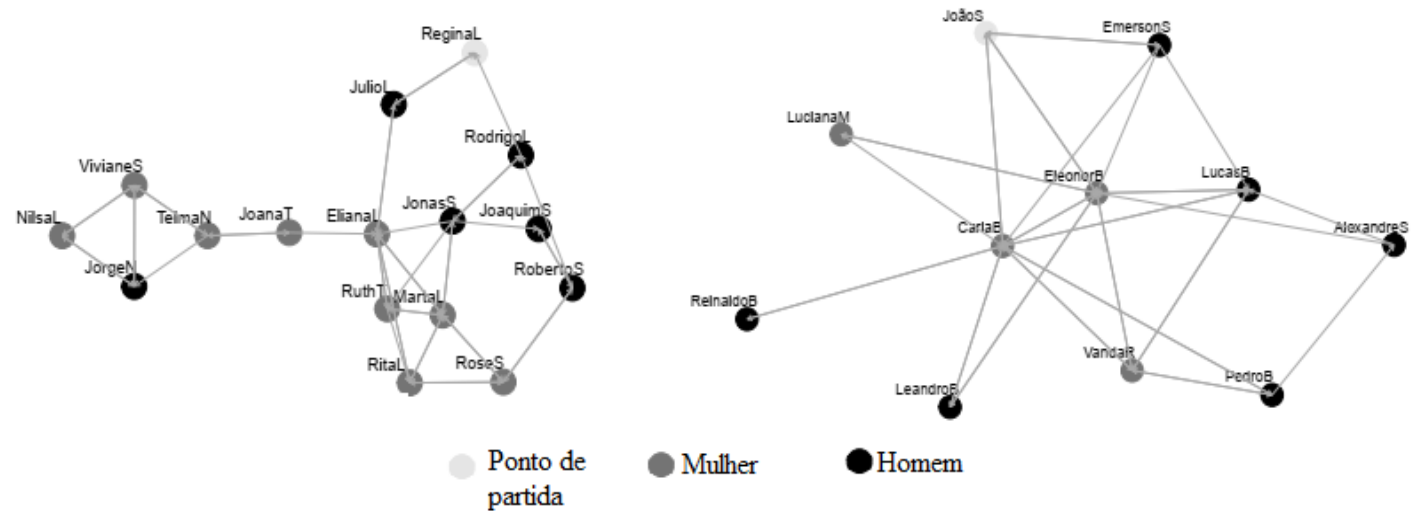

Fonte: Elaboração própria

4 A construção do corpus aqui utilizado ocorreu durante o mestrado da pesquisadora.

5 Todos os sujeitos da amostra assinaram o Termo de Consentimento Livre e Esclarecido (TCLE), permitindo o uso, para fins acadêmicos, das gravações de suas entrevistas.

6 Os nomes que aparecem na figura são fictícios para garantir a não divulgação de informações pessoais dos participantes da pesquisa. 
Ao analisar o padrão de vida dos integrantes de cada rede e os tipos de contatos que eles estabelecem, verificou-se que a rede fechada é assim definida porque seus integrantes pouco estabelecem relações com paulista(no)s e têm uma mobilidade geográfica mais reduzida, já que passam bastante tempo em seus bairros, conversam com vizinhos nordestinos e frequentam as casas de familiares que também são sergipanos. Por outro lado, os migrantes da rede aberta têm contatos mais rotineiros com paulista(no)s e se mobilizam geograficamente para além de seus bairros. Diante de tais diferenças, a pesquisa parte da hipótese de que os migrantes da rede fechada apresentam menores taxas de palatalização do que aqueles da rede aberta, justificada pelos tipos de contato que estabelecem em seu dia a dia.

Não houve um esforço para a criação de uma amostra estratificada por escolaridade e sexo/gênero, por exemplo, porque as relações estabelecidas entre os migrantes funcionaram como norteadoras. Contudo, em um estudo sociolinguístico, não deixa de ser interessante analisar a relevância de outros fatores sociais para os fenômenos linguísticos. Nesse sentido, os migrantes entrevistados foram divididos, parcialmente de modo equilibrado, dentro das seguintes categorias:

Tabela 1. Distribuição dos migrantes da amostra por Sexo/gênero e Escolaridade

\begin{tabular}{c|c|c}
\hline Variável social & Níveis & N \\
\hline \multirow{2}{*}{ Sexo/gênero } & Mulher & 14 \\
& Homem & 13 \\
\hline \multirow{3}{*}{ Escolaridade } & Fundamental I & 12 \\
& Fundamental II & 7 \\
& Médio & 8 \\
\hline
\end{tabular}

Fonte: Elaboração própria

Para a análise aqui desenvolvida, foram extraídas 80 ocorrências de /t, d/ diante de [i] de cada um dos entrevistados. Para tanto, os primeiros dez minutos das entrevistas foram desconsiderados de maneira a evitar que fossem extraídos dados de um momento em que os informantes estivessem mais constrangidos pela situação de gravação ${ }^{7}$.

A realização dos testes estatísticos se deu de duas maneiras. Em um primeiro momento, calcularam-se as diferenças, por meio de testes de qui-quadrado ${ }^{8}$, entre as frequências de usos das formas palatalizadas dos migrantes sergipanos e as dos sergipanos da

7 Em etapas futuras da investigação, pretende-se extrair as ocorrências por amostragem (ou seja, de modo aleatório), em vez de extrair os 80 dados em sequência, uma vez que os falantes podem variar seus usos durante a entrevista a depender do tópico abordado.

8 Testes de qui-quadrado são utilizados para o cálculo da probabilidade de que a hipótese nula seja verdadeira, a qual prevê que nenhum fator explique a variação dos dados (GUY, 2007). 
pesquisa de Souza (2016), com a intenção de verificar se aqueles estariam palatalizando mais frequentemente, de modo significativo do ponto de vista estatístico, que esses. Depois, foram criados modelos de regressão logística com efeitos mistos (BAAYEN, 2008) para verificar quais são as variáveis linguísticas e sociais relevantes para os padrões de variação observados na fala dos migrantes. Tais variáveis previsoras linguísticas e sociais são apresentadas resumidamente nos itens a seguir.

\section{Variáveis linguísticas}

As variáveis linguísticas analisadas para o fenômeno da palatalização foram elencadas a partir de estudos prévios sobre o fenômeno em questão (em situação de contato dialetal e no contexto sergipano), a saber:

(i) Contexto fonológico precedente, com a expectativa de que as fricativas alveolares favoreçam a pronúncia das formas palatalizadas (SOUZA, 2016; CORRÊA, 2019):

Quadro 1. Codificação da variável Contexto fonológico precedente ${ }^{9}$

\begin{tabular}{|c|c|c|}
\hline Contexto precedente & Segmentos & Exemplos de palavras \\
\hline Vogal baixa & {$[\mathrm{a}]$} & amizade, combate \\
\hline Vogal não baixa & {$\left[\mathrm{e}, \varepsilon, \mathrm{i}, \mathrm{o}, \mathrm{o}, \mathrm{u}, \mathrm{w}, \mathrm{j}^{10}\right]$} & rede, rodinha \\
\hline Fricativa alveolar & {$[\mathrm{s}, \mathrm{z}]$} & desde, vestido \\
\hline Rótico & {$[\mathrm{h}, \mathrm{s}, \mathrm{\tau}]$} & forte, parte \\
\hline Nasal & {$[\tilde{\mathrm{e}}, \tilde{\mathrm{e}}, \tilde{\mathrm{i}}, \tilde{\mathrm{o}}]$} & grande, vinte \\
\hline Início de palavra & - & dia, tipo \\
\hline
\end{tabular}

Fonte: Elaboração própria

(ii) Contexto fonológico posterior, em que as vogais posteriores favoreçam a palatalização (CORRÊA, 2019):

9 Tanto os níveis do Contexto fonológico precedente quanto os do Contexto fonológico posterior baseiam-se em Corrêa (2019), pois se intencionou manter certo grau de comparabilidade entre os estudos.

10 A inclusão de glides no subgrupo das "vogais não baixas" se deu pela sua baixa ocorrência no corpus. 
Quadro 2. Codificação da variável Contexto fonológico posterior

\begin{tabular}{|c|c|c|}
\hline Contexto posterior & Segmentos & Exemplos de palavras \\
\hline Vogal não posterior & {$[\mathrm{a}]$} & tia, podia \\
\hline Vogal posterior & {$[\mathrm{o}, \mathrm{o}, \mathrm{w}]$} & pátio, mandioca \\
\hline Oclusiva & {$[\mathrm{b}, \mathrm{d}, \mathrm{g}, \mathrm{k}, \mathrm{p}, \mathrm{t}]$} & ditado, atitude \\
\hline Fricativa & {$[\mathrm{f}, \mathrm{s}, \mathrm{v}, \mathrm{z}]$} & diferença, tive \\
\hline Nasal & $\lceil\mathrm{e}, \tilde{\mathrm{e}}, \tilde{\mathrm{i}}, \tilde{\mathrm{o}}, \mathrm{m}, \mathrm{n}, \mathrm{n}]$ & grande, time, vinte \\
\hline Líquida & {$[\lambda, \mathrm{r}]$} & direto, cartilha \\
\hline Fim de palavra & - & parede, pacote \\
\hline
\end{tabular}

Fonte: Elaboração própria

(iii) Sonoridade, se a consoante é surda ou sonora, pressupondo que o segmento surdo favoreça a palatalização (MARTINS, 2008; SOUZA, 2016; CORRÊA, 2019);

(iv) Tonicidade, com os níveis pretônica inicial (como em "direito"), pretônica não inicial ("condição"), tônica ("tive") e postônica ("combate"); com a expectativa de que a palatalização seja favorecida pelas postônicas (SOUZA, 2016; CORRÊA, 2019);

(v) Status da vogal alta, se a vogal-gatilho é fonológica (como em "dia") ou se fonética derivada de /e/ átono (como em "sorte"). Nesse caso, os dados de semivogais foram amalgamados com o grupo da vogal fonológica, em razão de seu baixíssimo número de ocorrências. Sendo assim, a expectativa é de que a vogal fonológica favoreça a palatalização (CORRÊA, 2019'11).

\section{Variáveis sociais}

Com base na literatura de estudos sobre a fala do migrante, elencaram-se as seguintes variáveis sociais: (i) Rede social, se aberta ou fechada (cf. a seção "A constituição do corpus"), com a expectativa de que os migrantes da rede mais aberta terão as maiores taxas de palatalização (BORTONI-RICARDO, 2011 [1985]); (ii) Idade de migração (analisada como uma variável contínua no presente estudo), baseando-se na hipótese de que os sujeitos que tenham migrado mais jovens apresentem traços linguísticos mais semelhantes à comunidade anfitriã (CHAMBERS, 1992; OUSHIRO, 2020); (iii) Escolaridade, com a conjectura de que os mais escolarizados apresentem maiores frequências das formas palatalizadas pelo fato de que tais segmentos linguísticos gozam de mais prestígio em Sergipe (FREITAG; SANTOS, 2015; CORRÊA, 2019). Além dessas variáveis, também

11 Corrêa (2019) indica que as semivogais favorecem a palatalização. 
será analisado (iv) Sexo/gênero dos entrevistados, na medida em que Bortoni-Ricardo (2011 [1985]) observou uma diferença nas frequências de uso das variáveis linguísticas analisadas quanto ao sexo dos migrantes, de modo que as mulheres desfavoreciam as formas mais prestigiadas na região em foco.

\section{Interpretando os dados}

A partir das 27 entrevistas sociolinguísticas coletadas, $2153^{12}$ ocorrências de /t, d/ diante de [i] foram extraídas, das quais 1321 foram realizadas como palatalizadas $(61,36 \%)$ e 832 como oclusivas (38,64\%). A partir dessas informações, é possível afırmar que as taxas de distribuição dos usos de /t, d/ diante de [i] entre as variantes palatal e oclusiva dos migrantes sergipanos entrevistados se distinguem daquelas verificadas por Souza (2016) entre os sergipanos que não migraram. As porcentagens dos usos das formas palatalizadas estão em negrito na tabela 2 para destacar a diferença que existe entre os sergipanos que não migraram e os que residem em São Paulo:

Tabela 2. Proporções dos usos de /t, d/ dos sergipanos de diferentes localidades e dos migrantes

\begin{tabular}{c|c|c|c|c|c}
\hline \multirow{2}{*}{ Subgrupos de falantes } & \multicolumn{2}{|c|}{ Palatalizada } & \multicolumn{2}{c|}{ Oclusiva } & \multirow{2}{*}{ Frequência absoluta } \\
\cline { 2 - 5 } & $\mathbf{N}$ & $\mathbf{\%}$ & $\mathbf{N}$ & $\mathbf{\%}$ & 1000 \\
\hline Aracaju & 217 & $\mathbf{2 1 , 7}$ & 783 & 78,3 & 1000 \\
\hline Lagarto & 66 & $\mathbf{6 , 6}$ & 934 & 93,4 & 1000 \\
\hline Itabaiana & 77 & $\mathbf{7 , 7}$ & 923 & 92,3 & 2153 \\
\hline Migrantes & 1321 & $\mathbf{6 1 , 3 6}$ & 832 & 38,64 & . \\
\hline
\end{tabular}

Fonte: Elaboração própria

Percebe-se que os migrantes apresentam uma taxa relativamente alta de palatalização até mesmo em comparação com os aracajuanos, subgrupo que abarca a maior frequência de uso das formas palatalizadas entre os sergipanos da amostra controle. Os testes de qui-quadrado mostram que os migrantes palatalizam significativamente mais $/ \mathrm{t}, \mathrm{d} /$ que os não migrantes:

12 Sete ocorrências foram excluídas da planilha final de dados porque haviam sido extraídas incorretamente (o contexto linguístico não permitia a palatalização). 
Tabela 3. Resultados dos testes de qui-quadrado

\begin{tabular}{c|c}
\hline Pares comparativos & Testes de qui-quadrado \\
\hline Migrantes - Aracaju & $\chi^{2}=792,47(1), p<0,001$ \\
\hline Migrantes - Lagarto & $\chi^{2}=1135,6(1), p<0,001$ \\
\hline Migrantes - Itabaiana & $\chi^{2}=1107(1), p<0,001$ \\
\hline
\end{tabular}

Fonte: Elaboração própria

Uma vez verificada a diferença entre os padrões de uso dos migrantes e dos sergipanos da amostra controle, apresentam-se, a seguir, os resultados de modelos de regressão logística criados para compreender com mais profundidade as variáveis relevantes para os usos somente dos migrantes. A apresentação dos resultados de tais modelos se inicia com as variáveis previsoras linguísticas.

\section{Variáveis linguísticas}

Os resultados das análises da regressão logística em modelo de efeitos mistos (BAAYEN, 2008) sobre os usos de /t, d/ diante de [i] pelos migrantes entrevistados, com base em Sonoridade, Tonicidade, Contexto fonológico precedente, Contexto fonológico posterior e Status da vogal alta, estão na tabela $4^{13}$. Antes, é importante esclarecer que os efeitos mistos se referem à inclusão tanto de efeitos fixos quanto de aleatórios no cálculo estatístico. Segundo Levshina (2015) e Oushiro (2016), efeitos aleatórios são elementos que mudam de estudo para estudo, por exemplo, informante e item lexical variam de estudo para estudo (porque pessoas diferentes são entrevistadas em cada pesquisa, assim como as palavras não necessariamente são as mesmas entre os estudos - umas aparecem mais e outras menos). Já os efeitos fixos são os que podem ser replicados entre as diferentes pesquisas, como sonoridade, tonicidade, sexo/gênero, escolaridade etc.. Em estudos como o que se apresenta aqui, recomenda-se a inclusão de efeitos mistos (isto é, tanto de efeitos fixos quanto de aleatórios) nas análises para verificar se há padrões gerais a despeito das particularidades dos informantes ou da frequência de palavras específicas.

13 É importante esclarecer que as variáveis sociais foram incluídas no mesmo modelo estatístico que é apresentado na Tabela 4. Contudo, seus resultados serão apresentados apenas na próxima seção. 
Tabela 4. Resultado da análise de regressão logística em modelo de efeitos mistos para o uso das formas palatalizadas de acordo com as variáveis linguísticas $(N=2153)$

$$
\text { Intercept }=8,376
$$

\begin{tabular}{|c|c|c|c|c|c|}
\hline & Estimativa & Erro padrão & Valor-z & $(p)$ & Apl./N \\
\hline \multicolumn{6}{|l|}{ Sonoridade } \\
\hline Sonora (v. referência) & & & & & 449/913 (49\%) \\
\hline Surda & 1,352 & 0,238 & 5,674 & $<0,001 * * *$ & $872 / 1240(70 \%)$ \\
\hline \multicolumn{6}{|l|}{ Tonicidade } \\
\hline \multicolumn{2}{|c|}{ Pretônica inicial (v. referência) } & & & & $170 / 328 \quad(52 \%)$ \\
\hline Postônica & 0,921 & 0,586 & 1,572 & 0,116 & $684 / 1069(64 \%)$ \\
\hline Pretônica não inicial & 1,015 & 0,589 & 1,725 & 0,084 & $78 / 111 \quad(70 \%)$ \\
\hline Tônica & 0,930 & 0,413 & 2,251 & $0,024 *$ & $389 / 645(60 \%)$ \\
\hline \multicolumn{6}{|c|}{ Contexto fonológico precedente } \\
\hline Vogal baixa (v. referência) & & & & & $122 / 253(48 \%)$ \\
\hline Fricativa alveolar & 2,952 & 0,741 & 3,987 & $<0,001^{\star \star \star}$ & $74 / 78 \quad(95 \%)$ \\
\hline Início de palavra & 0,341 & 0,489 & 0,696 & 0,486 & $434 / 784 \quad(55 \%)$ \\
\hline Nasal & 0,767 & 0,324 & 2,367 & 0,018 * & $501 / 725(69 \%)$ \\
\hline Rótico & 0,335 & 0,477 & 0,702 & 0,482 & $57 / 96 \quad(59 \%)$ \\
\hline Vogal não baixa & 0,681 & 0,369 & 1,848 & 0,065 & $133 / 217(61 \%)$ \\
\hline \multicolumn{6}{|c|}{ Contexto fonológico posterior } \\
\hline Fricativa (v. referência) & & & & & 233/395 (59\%) \\
\hline Fim de palavra & $-2,403$ & 0,460 & $-5,229$ & $<0,001 * \star \star$ & $634 / 1025(62 \%)$ \\
\hline Líquida & $-0,089$ & 0,573 & $-0,155$ & 0,877 & $25 / 43 \quad(58 \%)$ \\
\hline Nasal & $-0,120$ & 0,377 & $-0,317$ & 0,751 & $230 / 357 \quad(64 \%)$ \\
\hline Oclusiva & $-0,253$ & 0,411 & $-0,617$ & 0,537 & $94 / 138 \quad(68 \%)$ \\
\hline Vogal não posterior & $-0,868$ & 0,502 & $-1,728$ & 0,084 & $75 / 160 \quad(49 \%)$ \\
\hline Vogal posterior & 0,479 & 0,747 & 0,641 & 0,522 & $30 / 35$ \\
\hline \multicolumn{6}{|l|}{ Status da vogal } \\
\hline Fonética (v. referência) & & & & & $683 / 1078(63 \%)$ \\
\hline Fonológica & $-1,429$ & 0,391 & $-3,655$ & $<0,001 * \star \star$ & $638 / 1075(59 \%)$ \\
\hline
\end{tabular}

Modelo: glmer(VD SONORIDADE + TONICIDADE + CONT.PREC + CONT.POST + STATUS. VOGAL + V.SOCIAIS + (1|INFORMANTE $)+(1 \mid$ ITEM.LEXICAL), data = dados, family $=$ binomial)

Fonte: Elaboração própria 
Os números que são apresentados na coluna da estimativa se referem às chances de ocorrência da variante em foco, a qual, no presente caso, é a forma palatalizada (porque a análise objetiva identificar quem mais se aproxima do falar paulistano). $\mathrm{Na}$ primeira coluna, aparecem os níveis das variáveis linguísticas (e fixas) elencadas como possíveis fatores relevantes para o fenômeno estudado (isto é, os níveis de Sonoridade, de Tonicidade, de Contexto precedente, de Contexto posterior e de Status da vogal). 0 intercept, localizado no topo da tabela, diz respeito ao nível de referência, estipulado pela plataforma R a partir da ordem alfabética dos nomes dos níveis, logo, como "sonora" vem antes de "surda", "fonética" aparece antes de "fonológica" e assim sucessivamente, o nível de referência da tabela 4 é o segmento [dz] (consoante sonora) com vogal fonética [i] em sílaba pretônica, antecedida por uma vogal baixa e seguida por uma fricativa. É, no entanto, possível mudar a ordem em que os níveis aparecem na tabela. Isso explica por que o nível de referência da variável Tonicidade é "pretônica inicial" e não "postônica", e do Contexto fonológico precedente é "vogal baixa" e não "fricativa alveolar"14. Os valores da coluna estimativa devem ser lidos em logodds, medida essa que calcula as chances de algo ocorrer. A medida de logodds vai de $-\infty$ a $+\infty$, com ponto neutro em zero. Logo, "valores positivos indicam tendência a favorecimento (em relação a outro nível da mesma variável previsora); e valores negativos indicam tendência a desfavorecimento (em relação a outro nível da mesma variável previsora)" (OUSHIRO, 2017, p. 186). Se observarmos a linha do fator "surda", podemos afirmar que as chances de ocorrer a forma palatalizada [t]], em relação à sonora (o valor de referência), é de 1,352 logodds, ou seja, a consoante surda favorece a realização da palatalização (já que o valor 1,352 é maior que zero). Ademais, tal favorecimento é significativo do ponto de vista estatístico, pois se observa que o valor de $p$, na penúltima coluna, é menor que 0,001. Tem-se como convenção, nas ciências humanas (GRIES, 2013), que valores de $p$ menores que 0,05 indicam a rejeição da hipótese nula (a qual pressupõe que nenhum efeito esteja influenciando a variação dos dados).

O erro padrão, que aparece na terceira coluna da tabela, define-se como uma "medida de dispersão que dá indícios de quão precisa é a estimativa. Quanto maior o valor do erro padrão, maior é a variabilidade nas medições" (OUSHIRO, 2016, p. 42). O valor de z, por sua vez, apresentado na quarta coluna, é utilizado para o cálculo do valor de significância (p).

Observando a coluna do valor de $p$, percebemos que o nível "tônica" da variável Tonicidade é significativamente relevante para a variação, de modo que essa posição silábica favorece a palatalização (a estimativa 0,930 é positiva) em relação ao nível de referência (que é a "pretônica inicial"). Quanto à variável Contexto fonológico precedente, nota-se que dois de seus níveis favorecem a ocorrência das formas palatalizadas, em relação ao nível de referência ("vogal baixa"): as fricativas alveolares e as nasais. Em relação à variável

14 Essas mudanças foram realizadas para verificar se as postônicas e as fricativas alveolares favorecem ou não a palatalização em relação aos outros níveis (cf. as hipóteses descritas na seção "Variáveis linguísticas"). Caso elas fossem os níveis de referência da análise, tal visualização não seria possível. 
Contexto fonológico posterior, observa-se que "fim de palavra" desfavorece a palatalização em comparação ao nível de referência (que, nesse caso, é a fricativa alveolar). Finalmente, no que se refere ao Status da vogal alta, nota-se que as vogais fonológicas desfavorecem a palatalização em relação às fonéticas.

Recapitulando os resultados vistos até o momento, percebe-se que os níveis linguísticos que favorecem a palatalização de /t, d/ na fala dos migrantes sergipanos são: o segmento surdo, a posição tônica, as fricativas alveolares e as nasais em contexto fonológico precedente e as vogais fonéticas. Salienta-se que algumas dessas tendências divergem daquelas observadas por Souza (2016) e Corrêa (2019), cujos trabalhos apontam para a posição postônica e a vogal-gatilho fonológica como favoráveis ao processo de palatalização.

\section{Variáveis sociais}

Os resultados das análises de regressão logística em modelo de efeitos mistos no que se refere à palatalização de $/ \mathrm{t}, \mathrm{d} / \mathrm{n}$ n fala dos migrantes sergipanos em relação às variáveis sociais são apresentados na tabela 5. Primeiramente, destaca-se que não aparecem os resultados para as variáveis Rede e Sexo/gênero, pois ambas não têm efeito na pronúncia de /t, d/, o que foi verificado após uma série de análises realizadas na plataforma $R$. Isto é, na presente pesquisa, o modelo estatístico que melhor explica o padrão de uso de /t, d/ é aquele em que Rede e Sexo/gênero estão excluídas.

Tabela 5. Resultado da análise de regressão logística em modelo de efeitos mistos para o uso das formas palatalizadas de acordo com as variáveis sociais $(N=2153)$

\begin{tabular}{l|c|c|c|c|c}
\hline & Estimativa & Erro padrão & Valor-z & $(\boldsymbol{p})$ & Apl./N \\
\hline Idade de migração & $-0,418$ & 0,125 & $-3,339$ & $<0,001 * \star \star$ & \\
\hline Escolaridade & & & & & \\
\hline Fundamental II (v. referência) & & & & $292 / 560(52 \%)$ \\
\hline Fundamental I & $-7,034$ & 3,221 & $-2,184$ & $0,029 *$ & $567 / 959(59 \%)$ \\
\hline Médio & $-2,385$ & 3,115 & $-0,766$ & 0,444 & $462 / 634(73 \%)$ \\
\hline Interação & & & & & \\
\hline Fundl:Idade.Mig. & 0,376 & 0,154 & 2,440 & $0,015 *$ & \\
\hline Médio:Idade.Mig. & 0,175 & 0,156 & 1,123 & 0,261 & \\
\hline
\end{tabular}

Modelo: glmer(VD V.LINGUISTICAS + IDADE.MIG*ESCOLARIDADE + (1|INFORMANTE) $+(1$ IITEM.LEXICAL), data = dados, family = binomial $)$

Fonte: Elaboração própria

15 Conforme apontado na apresentação das variáveis sociais, idade de migração não apresenta níveis porque foi analisada como uma variável numérica. 
A tabela 5 indica, portanto, a ausência da variável Rede social, que não importa se o migrante estabeleceu mais ou menos contato com paulistanos em seu dia a dia no que se refere ao uso de /t, d/. No estudo de Bortoni-Ricardo (2011 [1985]), sobre a fala de migrantes rurais, a autora verificou que as redes sociais dos falantes analisados eram relevantes para as variáveis sintáticas (concordância verbal de $1^{\mathrm{a}}$ e $3^{\mathrm{a}}$ pessoas) no caso dos homens. Para as variáveis fonéticas, em contrapartida, outros fatores explicaram a variação observada nos dados: no caso da vocalização da lateral alveopalatal (mi $[\lambda]$ $\left.\mathrm{o} \rightarrow \mathrm{mi}\left[{ }^{[}\right] \mathrm{o}\right)$, a autora mostra que o índice de urbanização explica quem mais mantém a pronúncia do dialeto de origem e quem utiliza a variante da comunidade urbana. Bortoni-Ricardo explana que os migrantes que estavam mais integrados à cultura urbana dominante (no sentido de ter maior grau de escolarização, de ocupar cargos mais prestigiados, de se locomover mais frequentemente pelo centro urbano etc.) tendiam a utilizar mais vezes a variante não vocalizada. Quanto à redução do ditongo (dúz[j]a $\rightarrow$ dúz[Ø]a), ela explica que esse é um traço que está abaixo do nível de consciência social e que, portanto, entre os migrantes adultos analfabetos ou semialfabetizados, não existia uma "tendência em direção à eliminação de sua gramática" (BORTONI-RICARDO, 2011 [1985], p. 221). É interessante notar que, em tal pesquisa, existe uma relevância da estrutura das redes sociais no que se refere às variáveis morfossintáticas e não às fonéticas.

Além disso, também pela ausência da variável Sexo/gênero no modelo estatístico, não se verifica uma diferença significativa entre os usos das mulheres e dos homens, apesar de ser frequente na literatura sociolinguística um discurso de que as mulheres, comparativamente aos homens, são mais "sensíveis" às formas prestigiadas. BortoniRicardo (2011 [1985]) visualizou uma diferença entre os usos das mulheres e dos homens migrantes na região de Brazlândia, contudo, eram os homens que mais utilizavam as formas consideradas prestigiadas. A autora argumenta que tal configuração encontra amparo explicativo no fato de que as mulheres pouco mantinham contato com pessoas fora do ambiente doméstico, uma vez que a maioria delas era dona de casa. Sendo assim, eram os homens que estabeleciam contato com a cultura dominante e urbana, pois eles saíam para trabalhar e se relacionavam com pessoas de outras variedades linguísticas. O argumento de Bortoni-Ricardo, portanto, estrutura-se não apenas numa categoria macrossocial como sexo/gênero para explicar as diferenças nos usos das variantes. A pesquisadora estabelece ligações com outros fatores sociais para embasar seus resultados. Isso significa que o falar do migrante deve ser analisado levando-se em conta um conjunto de variáveis que atuam simultaneamente nos padrões de variação observáveis. Ou seja, mulheres e homens (migrantes ou não) falam de determinada maneira porque diversos fatores estão atuando em seus contextos sociais (ocupação, contatos, escolarização etc.) ao mesmo tempo.

Conforme foi aventado nas hipóteses do trabalho, a idade de migração tem efeito na palatalização de /t, d/ $(p<0,001)$ : quanto mais velha a pessoa tenha migrado, menores são as chances de ela palatalizar /t, d/ (por isso a estimativa é negativa: -0,418). Tal 
resultado converge com o de Oushiro (2020), cuja pesquisa analisa os padrões de variação de quatro variáveis linguísticas distintas na fala de 40 paraibanos e alagoanos residentes em Campinas (SP). Por meio da análise de duas variáveis fonéticas (pronúncia do / $\mathrm{r} /$ em coda e palatalização de /t, d/ diante de [i]) e duas morfossintáticas (formas de negação e concordância nominal), a autora revela que idade de migração se correlaciona aos usos das variáveis fonéticas, mas não das morfossintáticas: quanto mais novo tenha migrado o falante, maiores são suas frequências de uso das formas palatalizadas e de tepe e retroflexo (variantes predominantes no falar de Campinas). Portanto, ao reunir os resultados de Oushiro (2020) com os apresentados aqui, pode-se afirmar que idade de migração é um dos fatores que explicam as diferentes taxas de uso das variantes fonéticas da comunidade anfitriã pelos migrantes.

No que se refere à escolaridade dos sujeitos, destaca-se que, contra a expectativa da hipótese aventada, não se verifica, na tabela 5, uma diferença significativa entre os usos dos migrantes com ensino médio e aqueles com fundamental II (nota-se apenas que os migrantes que estudaram até o fundamental I desfavorecem a variante palatalizada estimativa de -7,034). Apesar de as formas palatalizadas serem prestigiadas em Sergipe, pelo menos entre os universitários e os com ensino superior completo (FREITAG; SANTOS, 2015), não se constata um favorecimento significativo ao fenômeno entre as pessoas com ensino médio na amostra de migrantes. O resultado obtido entre os migrantes faz emergir o questionamento sobre a consciência linguística dos entrevistados sobre tal variável. Na pesquisa de avaliação sobre as formas oclusivas e palatalizadas, Freitag e Santos (2015) assinalam para uma valorização das formas palatalizadas entre os universitários de Aracaju, mas não são apresentados resultados sobre aqueles que têm menos escolaridade. Nesse sentido, não é possível saber se há de fato uma valorização de tais variantes entre os menos escolarizados.

Finalmente, nas últimas linhas da tabela 5, observa-se a interação entre idade de migração e escolaridade, indicando que a idade de migração tem efeitos distintos a depender do grau de escolaridade do migrante. Essa diferença fica clara no gráfico 1 apresentado a seguir: 
Gráfico 1. Interação entre as variáveis escolaridade e idade de migração na análise de regressão logística em modelo de efeitos mistos para a palatalização de /t, d/ por migrantes sergipanos em São Paulo

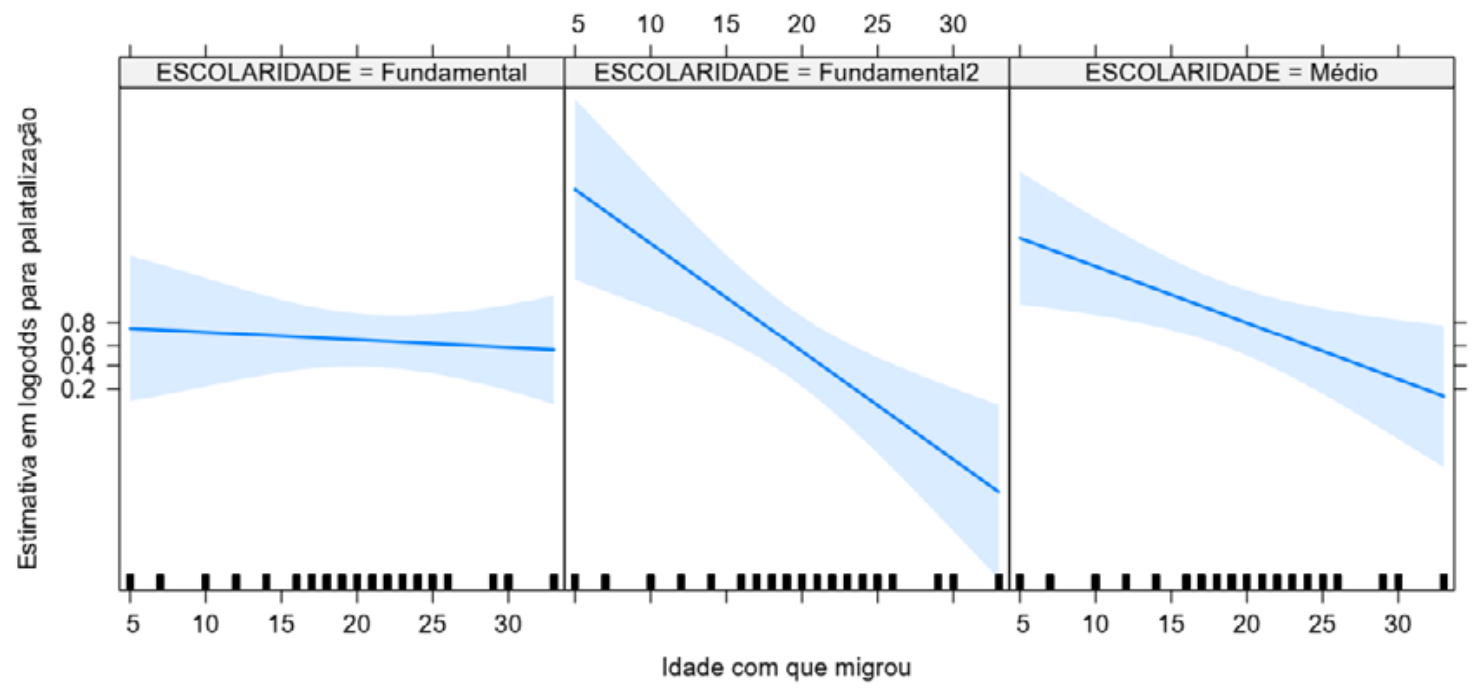

Fonte: Elaboração própria

Nota-se no gráfico 1 que, para os migrantes que estudaram até o ensino fundamental I, a idade de migração praticamente não faz diferença para o padrão de uso da palatalização. Por outro lado, para as demais escolaridades, existe uma tendência de diminuição da palatalização conforme aumenta a idade com que o falante migrou. Em virtude de tal resultado, foi averiguado o lugar onde os migrantes frequentaram a escola, se Sergipe ou São Paulo, com o intuito de compreender com mais clareza o contexto no qual ocorreu a formação escolar que eles têm. Dentre os migrantes que completaram o fundamental II ou o médio, com exceção de uma mulher, todos os demais estudaram já em São Paulo (alguns com a chamada Educação de Jovens e Adultos - EJA). Aqueles que cursaram somente o fundamental I, assim o fizeram ainda em Sergipe. Percebe-se, então, uma diferença bastante relevante entre esses migrantes, pois aqueles que estudaram em São Paulo entraram em contato com a variedade paulista(na) também em um ambiente mais formal, onde se almeja o ensino da norma-padrão. Embora o ensino de Língua Portuguesa tenha avançado no Brasil, com a inclusão do conhecimento científico nos documentos oficiais, como os Parâmetros Curriculares Nacionais (PCNs), a partir da década de 1990 (LUCCHESI, 2015), sabe-se que ainda é custosa, por parte das instituições de ensino, a legitimação das diferentes variedades de língua. Em face de tal contexto, é razoável afirmar que a escola teve um papel relevante como propulsora do uso das formas palatalizadas por aqueles que completaram seus estudos em São Paulo e que migraram mais jovens. Em contrapartida, os migrantes que estudaram apenas em Sergipe parecem não ter sofrido a mesma pressão social em direção à mudança em sua fala no que se refere a essa variável linguística. 
Em resumo, a partir dos resultados apresentados na tabela 5, é possível dizer que os usos da variável dependente aqui analisada são explicados pela idade com que o migrante mudou de estado e pelo lugar onde ele terminou seus estudos (se na região de origem ou na comunidade anfitriã). A questão de avaliação positiva associada a uma das variantes (o que resultaria em diferenças significativas nos usos entre quem estudou até o fundamental II e quem completou o médio) não parece ter um efeito nos dados analisados, tampouco sexo/gênero.

\section{Considerações finais}

A pesquisa apresentada nesse artigo objetivou verificar se os migrantes sergipanos, residentes em São Paulo, apresentavam frequências de uso das formas palatalizadas de /t, d/ diante de [i] maiores que os dos sergipanos que não migraram, a partir dos dados da pesquisa de Souza (2016), que estudou o fenômeno da palatalização na fala de indivíduos com nível superior de escolaridade ou universitários de três cidades distintas (Aracaju, Lagarto e Itabaiana). Os testes de qui-quadrado revelaram que os migrantes têm produzido significativamente taxas bastante superiores das formas palatalizadas do que os falantes que não migraram.

Atestadas tais diferenças, criaram-se modelos de regressão logística com efeitos mistos para averiguar quais as variáveis previsoras linguísticas e sociais que explicavam os padrões de uso dos migrantes. Para as linguísticas, o resultado do modelo indica que a palatalização é favorecida pela consoante surda, pela posição silábica tônica, por fricativas alveolares ou nasais que antecedem /t, d/ e pela vogal-gatilho fonética [i] derivada de /e/.

O resultado do modelo de regressão logística com efeitos mistos, por sua vez, assinala que a idade de migração e a escolaridade do falante são os fatores relevantes para o padrão de variação da pronúncia de $/ t$, $d /$ na fala dos migrantes sergipanos entrevistados. Os resultados, portanto, divergem da hipótese principal da pesquisa, que partia do pressuposto de que os migrantes da rede aberta palatalizariam mais frequentemente as consoantes em relação aos migrantes da rede fechada por conta do contato maior com paulista(no)s. Ademais, não se constataram diferenças entre as mulheres e os homens. A diferença que se observa entre os migrantes que estudaram até o fundamental I em comparação aos demais, com um desfavorecimento da palatalização na fala dos primeiros, parece ter mais relação com o lugar onde se deu a formação escolar dos indivíduos da amostra do que com uma questão de prestígio, diferentemente do verificado entre sergipanos universitários que não migraram (FREITAG; SANTOS, 2015). Isso posto, convém apontar para uma das limitações do presente estudo: apesar de não ter existido uma preocupação inicial em amostrar pessoas com ensino superior (cf. seção "A constituição do corpus"), ficou em aberto a pergunta de como se dá a mudança na fala de migrantes com ensino superior (será que as taxas de palatalização desse grupo são ainda maiores do que daquelas verificadas nas pessoas com menos escolarização?). 
O resultado do presente trabalho se junta ao que foi revelado por Chambers (1992) e Oushiro (2020), entre outros estudos sobre a fala de migrantes, sobre a importância da idade de migração do indivíduo como fator explicativo dos seus padrões de variação. Para encaminhamentos futuros, seria oportuno verificar se variáveis linguísticas de outros níveis, como o morfossintático ou o prosódico, também têm seus padrões de variação relacionados à idade de migração do falante ou da estrutura de suas redes sociais, como aqui foi aventado. Ou seja, a depender do nível linguístico da variável, os fatores sociais relevantes permanecem os mesmos ou não?

\section{Agradecimentos}

Agradeço à agência de fomento Capes pelo apoio fınanceiro para a realização da pesquisa de doutorado. Agradeço a Jesuel Marques Jr., Maria Eugênia Barcellos, Monique Freitas e Wendel Santos pelas generosas sugestões para a edição do texto. Agradeço também aos apontamentos dos(das) pareceristas que muito contribuíram para a melhoria do artigo.

\section{REFERÊNCIAS}

ABAURRE, M. B. M.; PAGOTTO, E. G. Consoantes em ataque silábico: palatalização de /t, d/. In: ABAURRE, M. B. M. (org.). Gramática do português culto falado no Brasil: a construção fonológica da palavra. São Paulo: Contexto, 2013. p. 195-236.

BAAYEN, R. H. Analysing linguistic data: a practical introduction to Statistics. Cambridge: Cambridge University Press, 2008.

BATTISTI, E.; DORNELLES FILHO, A. A. Análise em tempo real da palatalização de [t]] e [dz] no Português falado em uma comunidade ítalo-brasileira. Revista da ABRALIN, v. 14, n. 1, p. 221-246, ago. 2015. Disponível em: https://tinyurl.com/yxuvne2c. Acesso em: 26 ago. 2020.

BISOL, L.; HORA, D. Palatalização da oclusiva dental e fonologia lexical. Letras, n. 5, p. 26-40, jan./jun. 1993. Disponível em: https://periodicos.ufsm.br/letras/article/ view/11447/6921. Acesso em: 4 jun. 2021.

BORTONI-RICARDO, S. M. Do campo para a cidade: estudo sociolinguístico de migração e redes sociais. São Paulo: Parábola Editorial, 2011 [1985].

CARDOSO, S. A. M.; MOTA, J. A.; AGUILERA, V. A.; ARAGÃO, M. S. S.; ISQUERDO, A. N.; RAZKY, A.; MARGOTTI, F. W.; ALTENHOFEN, C. V. Atlas linguístico do Brasil. Londrina: EdUEL, 2014. 
CHAMBERS, J. K. Dialect acquisition. Language, v. 68, n. 4, p. 673-705, dez. 1992.

CORRÊA, T. R. A. A variação na realização de /t/ e /d/ na comunidade de práticas da UFS: mobilidade e integração. 2019. Dissertação (Mestrado em Letras) - Centro de Educação e Ciências Humanas, Universidade Federal de Sergipe, São Cristovão, 2019.

FREITAG, R. M. K.; SANTOS, O. A. Percepção e atitudes linguísticas em relação às africadas pós-alveolares em Sergipe. In: LOPES, N. S.; ARAÚJO, S. S. F.; FREITAG, R. M. K. (org.). A fala nordestina: entre a Sociolinguística e a Dialetologia. São Paulo: Blucher, 2016. p. 109-122. Disponível em: https://tinyurl.com/yxe53dpk. Acesso em: 26 ago. 2020.

GRIES, S. Statistics for Linguistics with R. 2nd edition. Berlin: Gruyter Mouton, 2013.

GUY, G. Introdução à análise quantitativa da variação lingüística. In: ZILLES, A.; GUY, G. Sociolingüística quantitativa: instrumental de análise. São Paulo: Parábola Editorial, 2007. p. 19-46.

LABOV, W. Padrões sociolinguísticos. São Paulo: Parábola Editorial, 2008 [1972].

LEVSHINA, N. How to do Linguistics with R. Amsterdam/Philadelphia: John Benjamins Publishing Company, 2015.

LUCCHESI, D. Língua e sociedade partidas: a polarização sociolinguística do Brasil. São Paulo: Contexto, 2015.

MARTINS, M. S. A palatalização de oclusivas dentais em contato dialetal. 2008.

Dissertação (Mestrado em Linguística) - Faculdade de Letras, Universidade Federal do Rio de Janeiro, Rio de Janeiro, 2008.

MILROY, L. Language and social networks. Oxford: Blackwell, 1987 [1980].

MILROY, L.; LLAMAS, C. Social networks. In: CHAMBERS, J. K.; TRUDGILL, P.; SCHILLINGESTES, N. (ed.). The handbook of language and change. 2. ed. Malden, MA: Blackwell, 2013 [2002]. p. 409-427.

OUSHIRO, L. Contrasting age of arrival and length of residence in dialect contact. Working Papers in Linguistics, v. 25, issue 2, jan. 2020. Disponível em: https://repository. upenn.edu/pwpl/vol25/iss2/10. Acesso em: 26 ago. 2020. 
OUSHIRO, L. Introdução à estatística para linguistas. Tutorial. v1.0.1, 2017.

OUSHIRO, L. A acomodação dialetal e a estabilidade de padrões sociolinguísticos na fala adulta. Relatório Científico de Pós-Doutorado, Universidade Federal do Rio de Janeiro, Rio de Janeiro, 2016.

PAGOTTO, E. G. Variação é identidade. 2001. Tese (Doutorado em Linguística) - Instituto de Estudos Linguísticos, Universidade Estadual de Campinas, Campinas, 2001.

SANTANA, A. L. As vogais médias pretônicas na fala de sergipanos em São Paulo. 2018. Dissertação (Mestrado em Letras) - Faculdade de Filosofia, Letras e Ciências Humanas, Universidade de São Paulo, São Paulo, 2018.

SIEGEL, J. Second dialect acquisition. New York: Cambridge University Press, 2010.

SOUZA, G. G. A. Palatalização de oclusivas alveolares em Sergipe. 2016. Dissertação (Mestrado em Letras) - Centro de Educação e Ciências Humanas, Universidade Federal de Sergipe, São Cristovão, 2016.

R CORE TEAM. R: A language and environment for statistical computing. R Foundation for Statistical Computing, Vienna, Austria. 2020. Disponível em: http://www.R-project.org/.

TRUDGILL, P. Dialects in Contact. Oxford: Blackwell, 1986. 